Revista Água Viva

ISSN 1678-7471

\title{
REFLEXÕES SOBRE CONJUGALIDADE E MATERNIDADE NO CONTO $A$ IMITAÇÃO DA ROSA, DE CLARICE LISPECTOR ${ }^{1}$ \\ REFLECTIONS ON CONJUGALITY AND MOTHERHOOD IN THE SHORT STORY A IMITAÇÃO DA ROSA [THE IMITATION OF THE ROSE], BY CLARICE LISPECTOR
}

Pollianna de Fátima Santos Freire ${ }^{2}$

Recebido em: 13 nov. 2019.

Aceito em: 23 mar. 2020

DOI 10.26512/aguaviva.v5i2.27197

RESUMO: Considerando-se que, na nossa sociedade, o "casamento e a maternidade como seu corolário aparecem [...] como o locus ideal do feminino" (NAVARRO-SWAIN, 2007, p. 210) e, na ordem do sistema patriarcal, "a capacidade específica de procriação do feminino torna-se o próprio feminino [...] cuja existência se justifica pela sua capacidade de reprodução" (NAVARRO-SWAIN, 2007, p. 220-221), analisarei o conto "A imitação da rosa", presente em Laços de Família (1960), a fim de discutir sobre dispositivos do sistema sexo/gênero que, ao longo dos séculos, vêm operando como mecanismos de opressão das mulheres. Entendendo que o principal discurso simbólico do sistema representacional do patriarcado presente neste conto está relacionado à incapacidade de procriação de Laura e, consequentemente, ao não exercício da maternidade, pretende-se discutir, a partir de uma visão teórica foucaltiana, sobre as estratégias adotadas pela personagem para resistir a esses mecanismos de opressão bem como discutir, ainda, em que medida o espaço heterotópico é explorado nessa narrativa como estratégia de resistência.

Palavras-chave: Clarice Lispector. Maternidade. Conjugalidade. Literatura de autoria feminina.

ABSTRACT: Considering that, in our society, "marriage and motherhood as their corollary appear ... as the Ideal locus of the feminine" (NAVARRO-SWAIN, 2007: 210) and, in the order of the patriarchal system, "the feminine capacity of procreation becomes the feminine itself ...

\footnotetext{
${ }^{1}$ Este artigo é resultado de parte das discussões desenvolvidas na minha dissertação de mestrado.

2 Integrante do grupo de Estudos em Literatura Brasileira Contemporânea - Gelbc (UnB). Foi investigadora predoutoral visitante em ADHUC-Centro de Investigación Teoría, Género, Sexualidad na Universidade de Barcelona. Doutoranda em Literatura e Práticas Sociais pelo Programa de Pós-Graduação em Literatura (Pós-Lit) da Universidade de Brasília (UnB). Mestra em Literatura e Práticas Sociais pelo Programa de Pós-Graduação em Literatura (Pós-Lit) da Universidade de Brasília (UnB). Graduada em Letras com Habilitação em Português e Literatura de Língua Portuguesa pela Universidade do Estado da Bahia (Uneb). E-mail: freirepdfs@gmail.com
} 
whose existence is justified by its reproductive capacity" (NAVARRO-SWAIN, 2007, pp. 220221), I will analyze the tale "A imitação da Rosa" [The Imitation of the Rose], from Laços de Família [Family Ties] 1(960), in order to discuss the devices of the sex / gender system that have been operating as mechanisms of oppression of women over the centuries. The main symbolic discourse of the representational system of patriarchy in this short story is related to Laura's inability to procreate and, consequently, to the non-exercise of motherhood, hence, we intend to discuss, from a Foucaultian theoretical perspective, the strategies the character adopts to resist these mechanisms of oppression as well as discuss to what extent the heterotopic space is explored in this narrative as a strategy of resistance.

Keywords: Clarice Lispector. Motherhood. Conjugality. Women's literature.

\section{INTRODUÇÃO}

A partir do movimento feminista, a mulher passou a ser objeto de estudo em diversas áreas do conhecimento, a exemplo da literatura, o que, por conseguinte, tem possibilitado a realização de trabalhos que investigam e questionam a condição de subjugada da mulher no contexto da representação e da produção literária. De acordo com Lúcia Zolin, em seu texto "Crítica Feminista", a crítica literária, entendida como uma instância política, viabiliza uma leitura do texto literário de modo "confessadamente empenhado, voltado para a desconstrução do caráter discriminatório das ideologias de gênero, construídas, ao longo do tempo, pela cultura" (ZOLIN, 2009b, p. 218). Assim, com base nas considerações de Zolin e na perspectiva teórica de Teresa de Lauretis, que, em seu artigo “A tecnologia do gênero", propõe que o gênero seja concebido como uma representação articulada por meio de diversas "tecnologias", tais como a família, as escolas, os meios de comunicação, a academia, os tribunais, os movimentos sociais - a exemplo dos feminismos - e as práticas artísticas - a exemplo da literatura, é que me interessa discutir, neste artigo, a representação de dispositivos discursivos do sistema sexo/gênero, a exemplo da conjugalidade e da maternidade, em narrativas da literatura de autoria feminina.

Para tanto, escolhi para análise central neste texto o conto "A imitação da Rosa", compilado na coletânea Laços de Família (1960), de Clarice Lispector, devido ao fato de essa escritora ter inaugurado uma fase da literatura de autoria feminina no Brasil que ofereceu novas perspectivas em relação à posição que a mulher ocupava no cenário da produção literária nacional. Também de acordo com Zolin, em seu artigo "Literatura de Autoria Feminina", a obra de Clarice Lispector representou um momento de ruptura com a reprodução dos valores 
patriarcais que, até então, marcava a produção literária de autoria feminina, ou seja, Lispector marca, no Brasil, o início da fase feminista da literatura de autoria feminina, na medida em que a produção literária da escritora "traz em seu bojo críticas contundentes aos valores patriarcais, tornando visível a repressão feminina nas práticas sociais, numa espécie de consequência do processo de conscientização desencadeado pelo feminismo.” (ZOLIN, 2009a, p. 332)

No que se refere à literatura de autoria feminina, Zolin (2009a, p. 329-330) explica, ainda, que o termo "fase feminista" refere-se a uma das categorias utilizadas pela ensaísta norteamericana Elaine Showalter, em seu trabalho "A Literature of Their Own: British Womem Novelists from Brönte to Lessing”, para delimitar as especificidades que marcam a produção de autoria feminina em um determinado momento histórico, observando as maneiras pelas quais a autoconsciência da mulher traduziu-se na literatura por ela produzida em um tempo e espaço determinados e como ela se desenvolveu. Na concepção da ensaísta, todas as subculturas literárias percorrem três grandes fases: a de imitação e de internalização dos padrões dominantes; a fase de protesto contra tais padrões e valores; e a fase de autodescoberta, marcada pela busca da identidade própria.

Segundo a pesquisadora brasileira, adaptando essas fases às especificidades da literatura de autoria feminina, tem-se a fase feminina, feminista e fêmea (ou mulher), respectivamente. Na literatura produzida no Brasil, a fase feminina teria se iniciado com a publicação de Úrsula (1859), de Maria Firmina dos Reis, e se estendido até 1944, quando Clarice Lispector inaugura a sua produção com a publicação de Perto do Coração Selvagem. Nesse sentido, Zolin argumenta que a obra de Lispector se estrutura em torno das relações de gênero que trazem à tona as diferenças sociais cristalizadas entre os sexos, as quais cerceiam quaisquer possibilidades de a mulher atingir a sua plenitude existencial. Trata-se, portanto, de a escritora inaugurar uma nova fase da trajetória de literatura brasileira de autoria feminina no Brasil feminista, na terminologia de Showalter - marcada pelo protesto e pela ruptura em relação aos valores dominantes.

Assim, partindo da ideia de que, nessa nova fase de produção da literatura de autoria feminina, as escritoras começaram a se permitir a questionar os modelos femininos de submissão herdados da sociedade patriarcal bem como passaram a representar essas angústias na ficção, discutirei, com base no conto em questão, quais são os principais discursos simbólicos do sistema representacional do patriarcado que estão operando nessa narrativa como mecanismos de opressão feminina. 


\section{A imitação do patriarcado ${ }^{3}$}

Por acaso alguém veria, naquela mínima ponta de surpresa que havia no fundo de seus olhos, alguém veria nesse mínimo ponto ofendido a falta dos filhos que ela nunca tivera? (LISPECTOR, 2009, p. 35)

No conto A Imitação da Rosa, a voz da narrativa nos apresenta Laura, uma mulher oprimida pela moral patriarcal e que luta para manter a sanidade diante da impossibilidade de responder às expectativas das convenções instituídas pelo casamento e pela educação burguesa. Logo no início da narrativa, a referência ao estado de saúde da personagem — quando a voz da narrativa menciona que Laura voltara a ficar "bem" —; a referência a enfermeiras e médicos; e, ainda, a insistente preocupação em manter as coisas da casa em ordem, como que para ter a sensação de controle das próprias ações, denotam que Laura enfrentava uma crise pessoal que, anteriormente, já a havia levado, provavelmente, a uma internação em uma clínica psiquiátrica. A personagem, durante uma tarde em que se prepara para jantar com o marido e com um casal de amigos, mergulha em um monólogo interior e vai evidenciando os motivos que, possivelmente, a levaram ao estado de descontrole emocional.

Em seu livro, Nem musa, nem medusa, a pesquisadora Lúcia Helena, ao analisar o conto em questão, explora algumas das várias possibilidades interpretativas do vocábulo imitação que compõe o título da narrativa. Entre essas possibilidades, a autora destaca três sentidos produzidos pelo vocábulo em “A imitação da Rosa”, que, na sua concepção, são essenciais para a compreensão da tessitura da narrativa: a imitação do patriarcado, a imitação das rosas e a imitação de Cristo. Em seu trabalho, a autora analisa as tensões e inter-relações entre a imitação do patriarcado e a imitação das rosas, aspectos esses que ela considera centrais para a narrativa, para, por fim, tecer uma breve reflexão sobre o simbolismo da imitação de Cristo. Acerca das significações produzidas pela imitação do patriarcado nesse conto de Clarice Lispector, Lúcia Helena considera que:

\footnotetext{
${ }^{3} \mathrm{O}$ termo é utilizado em referência aos usos que Lúcia Helena faz em seu livro Nem musa, nem medusa, no qual discorre sobre a representação da mulher burguesa em narrativas de Clarice Lispector. Ademais, mesmo reconhecendo as limitações do termo patriarcado, ele será utilizado porque está sendo compreendido, aqui, como "o poder efetivo e socialmente sancionado da figura do pai dentro do núcleo familiar" (OLIVEIRA, 2004, p. 103). Ademais, ainda nos baseamos nas colocações de Carole Pateman sobre o patriarcalismo, que explica que este, por sua vez, "se baseia no apelo à natureza e no argumento de que a função natural da mulher de procriar prescreve seu lugar doméstico e subordinado na ordem das coisas" (PATEMAN, 2013, p. 62).
} 
Tomando como modelo a família nuclear brasileira de classe média, composta de uma mulher tijucana que passa do pai para o marido, por meio da bênção de um padre, o conto de Lispector questiona um sistema de gender não apenas nacional ou regional, mas um sistema que nem diz respeito ao Brasil, nem mesmo à América Latina. Através das complexas relações de sentido operacionalizadas no texto de Lispector, o que está sendo criticado é a ideologia de um sistema de trocas simbólicas largamente difundido, e no qual se correlaciona o gender a conteúdos culturais (numa genderização da cultura), de acordo com os valores sociais desenvolvidos pela tradição judaico-cristã. Valores que estabelecem o 'sex-gender system' que organiza posições ideológicas, ao representar o "feminino", o 'masculino', o 'sujeito' e a 'subjetividade' como identidades estáveis e universalizantes. 'A Imitação da Rosa' remete seu leitor a uma crítica do suporte ideológico dessas representações, ao fixar não só os danos que as imposições de gender provocam, mas também o fato de que estas essências são instáveis e estão sujeitas, do mesmo modo que a protagonista Laura, à metamorfose e à repetição (HELENA, 1997, p. 55-56).

Devido ao fato de a obra da autora Clarice Lispector apresentar uma fortuna crítica vasta e consolidada, essa narrativa já foi objeto de estudo de inúmeros trabalhos - a exemplo do texto de Lúcia Helena, principal referência desta análise. A maioria desses trabalhos explora as aproximações existentes entre as relações conjugais delineadas por Clarice Lispector, principalmente em sua coletânea Laços de Família, e o ideal de família burguesa. Nesse sentido, saliento que, aqui, discutirei, a partir da categorização proposta por Helena, alguns pontos somente sob o viés da imitação do patriarcado, a fim de identificar, de modo mais pontual, quais são os principais discursos simbólicos do sistema representacional do patriarcado que estão operando nessa narrativa como mecanismos de opressão feminina.

Na narrativa "A Imitação da Rosa”, a personagem Laura, mulher "castanha como obscuramente achava que uma esposa devia ser" (LISPECTOR, 2009, p. 41), timidamente tenta voltar a sua rotina de mulher casada e de dona de casa, após ter passado um período, provavelmente, internada em uma clínica psiquiátrica. Por meio de seus monólogos interiores, após conjecturar que voltara a ficar de novo "bem”, a personagem, aparentemente, insiste em reforçar um discurso fundado nos valores da moral patriarcal para tentar se convencer dele. A personagem vai, então, denotando sua insistente preocupação em cuidar ordeiramente da casa, em agradar Armando - o esposo — , em cuidar para manter-se insignificante enquanto mulher e esposa, e em parecer "bem" diante dos amigos, pessoas que, segundo a voz da narrativa, a ajudavam no sentido de "fazê-la sentir que agora estava 'bem"” (LISPECTOR, 2009, p. 35) e 
também a ajudavam a esquecer "fingindo elas próprias o esquecimento." (LISPECTOR, 2009, p. 35).

Entretanto, no decorrer da narrativa, ao mesmo tempo em que tenta reproduzir e tornar legítimo por meio dos seus monólogos interiores o discurso de esposa resignada e satisfeita com a submissão e a obediência ao marido e aos padrões impostos pelos laços conjugais e pela educação conservadora, a personagem denota que ela própria representa uma fissura nesse mesmo discurso, já que não conseguiu gerar filhos e constituir uma verdadeira família burguesa. A passagem do conto que evidencia a angústia de Laura por não ter gerado filhos é narrada no momento em que a personagem se prostra diante de um espelho, símbolo que, em várias narrativas de Lispector ${ }^{4}$, abarca, conforme denota a crítica sobre esse elemento na obra da autora, uma multiplicidade de sentidos:

Interrompendo a arrumação da penteadeira, Laura olhou-se no espelho: e ela mesma, há quanto tempo? Seu rosto tinha uma graça doméstica, os cabelos eram presos com grampos atrás das orelhas grandes e pálidas. Os olhos marrons, os cabelos marrons, a pele morena e suave, tudo dava a seu rosto não muito moço um ar modesto de mulher. Por acaso alguém veria, naquela mínima ponta de surpresa que havia no fundo de seus olhos, alguém veria nesse mínimo ponto ofendido a falta dos filhos que ela nunca tivera? (LISPECTOR, 2009, p. 35).

Essa passagem em que a voz da narrativa questiona-se sobre a possibilidade de os outros enxergarem em seus olhos aquele "mínimo ponto ofendido", ou seja, a angústia gerada pelo fato de não ter-se tornado mãe, é entendida aqui como o momento da narrativa que, sutilmente, revela os motivos que desencadearam as tensões que culminaram no desequilíbrio emocional de Laura. Sobre essa mesma passagem do conto, Maria Lúcia Homem, em seu artigo "A Imitação da Rosa - Encontro com o silêncio ou encontro com o feminino e a falta", considera que

Somente nesse momento surge o nome da protagonista - primeira vez que o narrador enuncia 'Laura', nome que vem junto com sua imagem no espelho. Nome e imagem, dois invólucros desse sujeito feminino que de fato parece

\footnotetext{
${ }^{4}$ Por exemplo, na narrativa "Os obedientes", compilado, primeiramente, na coletânea A legião estrangeira (1964) e, posteriormente, na coletânea Felicidade Clandestina (1971), a mulher comete suicídio após quebrar um dente e mirar-se no espelho.
} 
não ter lugar, perdido que está no anônimo marrom que o rodeia. No meio da arrumação da penteadeira, o leitor pode apreender uma primeira quebra no equilíbrio forjado [...] Ao se deparar com a sua própria imagem é que a personagem sofre, quase inadvertidamente, o confronto com aquilo que buscava evitar ou deixar adormecido. Vê aí, nesse mínimo ponto, o reflexo que brilha e que não a deixa esquecer de duas limitações ou a falta da maternidade como frustração em sua vida de mulher casada e do lar (HOMEM, 2004, p. 53-54).

Laura, diferentemente da personagem Ana ${ }^{5}$, do conto "Amor", que conseguiu constituir uma "família verdadeira", já que tivera "filhos verdadeiros" (LISPECTOR, 2009, p. 20), não conseguiu gerar filhos. Como na nossa sociedade o "casamento e a maternidade como seu corolário aparecem [...] como o locus ideal do feminino" (NAVARRO-SWAIN, 2007, p. 210) e, na ordem do sistema patriarcal, "a capacidade específica de procriação do feminino torna-se o próprio feminino [...] cuja existência se justifica pela sua capacidade de reprodução" (NAVARRO-SWAIN, 2007, p. 220-221), entendo que o principal discurso simbólico do sistema sexo/gênero presente no conto está relacionado à incapacidade de procriação de Laura e, consequentemente, ao não exercício da maternidade.

Tânia Navarro Swain (2007, p. 207), em seu artigo “Meu corpo é um útero?”, explica que as categorias de "mãe e esposa, família, sexo domesticado, moralidade, espaço privado, reprodução social" habitam o imaginário feminino e são utilizadas como parâmetro para definir a "verdadeira mulher". De acordo com a autora, essas categorias, "fundadas nas premissas da heterossexualidade e nas matrizes institucionais do patriarcado" (NAVARRO-SWAIN, 2007, p. 207), passaram, ao longo dos séculos, a representar socialmente o feminino:

Às mulheres tem-se tentado, há quatro ou cinco séculos, no Ocidente, atribuir um modelo, uma forma singular centrada em seu corpo, em sua capacidade reprodutora. Louvada enquanto apanágio das mulheres, a capacidade de procriação tem, por outro lado, o peso de um destino, de uma fatalidade que definiria as mulheres enquanto a verdadeira mulher. Esta imagem, tão difundida pelas instituições sociais, na iteração de um discurso construtor de corpos disciplinados, vem moldando as representações do feminino e a autorrepresentação das mulheres em torno da figura da mãe (NAVARROSWAIN, 2007, p. 203).

\footnotetext{
${ }^{5}$ Ana, personagem principal do conto “Amor”, também compilado em Laços de Família, é uma mulher que se esforça para se adequar ao padrão/modelo de mulher burguesa. Diferentemente de Laura, Ana tem filhos que, segundo a voz da narrativa, a afastam do "perigo de viver".
} 
Na narrativa, Laura é representada como uma mulher que, ao não se tornar mãe, perde a sua inteligibilidade social e, como todas as outras mulheres que não podem ou não querem ter filhos, é considerada uma mulher que não se realizou no mundo. Nessa perspectiva, NavarroSwain (2007, p. 204) argumenta que, embora a maternidade e o instinto materno, enquanto sentidos produzidos pelo patriarcado para legitimar a dominação de um sexo sobre o outro, estejam sendo desconstruídos pelos feminismos, ainda há questões centrais e emergenciais que devem ser repensadas pelos movimentos feministas no que se refere à categoria "mãe", cultivada pelo imaginário social como modelo de mulher. $\mathrm{O}$ principal questionamento levantado pela autora se refere ao lugar social das mulheres que não querem ou não podem ter filhos, a exemplo de Laura.

Para Navarro-Swain (2007), esse tipo de questionamento ainda desafia as agendas feministas porque, ainda que a heterossexualidade compulsória, entendida como um dos mecanismos de controle dos corpos das mulheres, esteja sendo discutida pelos feminismos, a maternidade continua sendo entendida como o principal fator de realização pessoal das mulheres. Segundo a autora, ainda é grande o número de mulheres, incluindo aquelas libertas das relações heterossexuais, que buscam a maternidade como fundamento familiar. Como aparato discursivo, a maternidade constitui um dos principais mecanismos de subordinação decorrentes das maneiras como a mulher é construída socialmente.

As colocações da autora ajudam a entender o porquê de o modelo de mulher centrado na reprodução e na maternidade ser, até hoje, detentor de uma força homogeneizante e excludente que reforça a ideia da divisão binária de papéis e a diferenciação entre os sexos. $\mathrm{O}$ casamento e a maternidade ainda habitam o imaginário social como condições para que as mulheres se sintam completas, felizes e realizadas. Nesse contexto, resta às mulheres que não podem, ou simplesmente não querem ter filhos, o peso do estigma de fugirem ao seu destino biológico e a perda de sua inteligibilidade social. Como a cobrança social é ainda maior em relação àquelas que são casadas, essas mulheres que são impossibilitadas de gerar filhos sofrem com o sentimento de angústia, com a culpabilidade, com o sentimento de inferioridade e com a vergonha, sentidos usados no processo de assujeitamento das mulheres devido ao fato de não terem sido capazes de dar um filho aos maridos. O papel de mãe é um sentido usado para justificar a existência das mulheres e atribuir-lhes uma identidade social. Ainda segundo Navarro-Swain: 
procriar, reproduzir a espécie passou a significar socialmente o feminino e esta significação social chama-se maternidade. Por um lado, a maternidade é louvada e incensada, objetivando-se na figura da mãe; por outro, torna-se uma fatalidade, na medida em que deixam de ser mulheres a imensa legião daquelas que não querem ou não podem ter filhos; perdem sua inteligibilidade social e alinham-se na fileira dos excluídos. A mãe é o modelo de mulher, a mulher no singular, uma figura fractal, que reproduz infinitamente a mesma imagem, reduzida a um sentido unívoco do ser (NAVARRO-SWAIN, 2007, p. 204).

Portanto, ao entender a maternidade como "um sentido social que aprisiona e desenha os corpos, os desejos e o ser no feminino" (NAVARRO-SWAIN, 2007, p. 220), parto do pressuposto de que a personagem "Laura, a imitadora do patriarcado, aquela que o reproduz na repressão a que condena a si própria" (HELENA, 1997, p. 56), impossibilitada de atender plenamente às expectativas que se tem de uma mulher burguesa na sociedade conjugal, encontra na loucura o único espaço simbólico viável para resistir à cobrança social que reduz a sua existência a um útero infrutífero. A maternidade, esta significação social instituída como o principal parâmetro para definir as "verdadeiras mulheres", é explorada, nesse conto, como um dos principais sentidos de assujeitamento utilizados pelo patriarcado para oprimir as mulheres nas sociedades conjugais.

A personagem Laura, ao sentir abater sobre si o cansaço gerado pela tortura a qual era submetida cotidianamente pela violência das cobranças para que atendesse expectativas patriarcais, marcadas, principalmente, pela dor e pelo peso do estigma de ser uma mulher estéril, encontra na loucura a única saída possível para lidar com as suas fragilidades e o seu aprisionamento. A passagem da narrativa em que são reveladas ao leitor as causas da esterilidade de Laura, uma insuficiência ovariana, é marcada pela repetição, entendida, nessa análise, como recurso linguístico utilizado pela autora para marcar, na narrativa, o indício do retorno do descontrole emocional da personagem e, consequentemente, a perda do controle das próprias ações:

E, de volta à paz noturna da Tijuca [...] de volta à sua verdadeira vida: ela iria de braço dado com Armando, andando devagar para o ponto de ônibus, com aquelas coxas baixas e grossas que a cinta empacotava numa só fazendo dela uma 'senhora distinta'; mas quando, sem jeito, ela dizia a Armando que isso 
vinha de insuficiência ovariana, ele, que se sentia lisonjeado com as coxas de sua mulher, respondia como muita audácia: 'De que me adiantava casar com uma bailarina?', era isso o que ele respondia. Ninguém diria, mas Armando podia ser às vezes muito malicioso, ninguém diria. De vez em quando eles diziam a mesma coisa. Ela explicava que era por causa de insuficiência ovariana. Então ele falava assim: 'De que me adianta ser casado com uma bailarina?' Às vezes ele era muito sem vergonha, ninguém diria (LISPECTOR, 2009, p. 40-41).

A pesquisadora Lúcia Helena, ainda em seu texto Nem musa nem medusa, afirma que as tensões vivenciadas por Laura refletem um movimento identificado em todas as personagens femininas da coletânea Laços de Família: a incapacidade daquelas mulheres de gerarem a própria autonomia. No entanto, é importante salientar que, mesmo incapazes de gerar a própria autonomia, personagens como Ana, do conto "Amor", e Laura, de “A Imitação da Rosa", adotam diferentes tipos de mecanismos de resistência para lidar com as suas tensões pessoais. Com relação às personagens femininas delineadas por Clarice Lispector na coletânea supramencionada, Lúcia Helena ainda afirma que:

\begin{abstract}
As mulheres de Laços de Família [...] são incapazes de gerar a sua própria autonomia. Tal estirpe de mulheres encontra na Laura de 'A Imitação da Rosa' um tipo exemplar, no qual se pode ver o conjunto de nuances através das quais Lispector simultaneamente redime e faz falir a vivência dessas 'mulheres', em seu debater-se numa espécie de prisão domiciliar e emocional. Fiel à ambiguidade que percorre a obra, por um lado, Laura é a imagem em espelho de uma sociedade patriarcal, pois todos os seus atos são um reflexo da tentativa de não se contrapor a Armando, o marido e, subservientemente, respeitar as convenções patriarcais instituídas pelo casamento, pela educação e pela religião católica. Por outro lado, durante todo o tempo em que ela faz este movimento de aceitação e passividade, desenvolve-se no texto o movimento contrário (HELENA, 1997, p. 45).
\end{abstract}

Nesse sentido, os diferentes tipos de mecanismos adotados por personagens dessa coletânea colocam em evidência os discursos simbólicos do sistema patriarcal que são utilizados no processo de assujeitamento das mulheres nas sociedades conjugais, além de funcionarem como estratégia para questionar esses mesmos dispositivos discursivos. No caso de Laura, a loucura é, ainda, a estratégia que movimenta a personagem e faz com que ela atue como instância crítica aos discursos simbólicos do sistema representacional do patriarcado que estão presentes na narrativa. Apesar da insistente preocupação em seguir as normas sociais, ela 
adota um comportamento que representa um desvio em relação à média ou à norma exigida; impossibilitada de gerir as próprias relações pessoais e afetivas, ela encontra na loucura o espaço que lhe fora negado no meio social.

No ensaio intitulado "Outros espaços", Michel Foucault desenvolve conceitos acerca dos espaços que podem servir para refletir sobre o espaço social e simbólico designado à personagem Laura nessa narrativa. Resumidamente, esses conceitos são: as utopias, entendidas como posicionamentos fora da realidade, e as heterotopias, entendidas como os lugares que, ainda que sejam localizáveis, constituem uma espécie de contestação ao mesmo tempo mítica e real do espaço em que vivemos. Ao construir tais conceitos, o autor propõe uma sistematização do estudo das heterotopias identificando nelas cinco princípios básicos. Aqui, entretanto, me deterei apenas nas ideias relacionadas ao primeiro princípio, já que ele será central para as relações que serão estabelecidas entre o conceito de heterotopia e as estratégias de resistência adotadas pela personagem no texto ficcional.

Com relação a esse primeiro princípio, o autor afirma que, provavelmente, não há uma única cultura no mundo que não se constitua de heterotopias; estas, por sua vez, assumem formas muito variadas e podem ser classificadas em dois grandes tipos: as heterotopias de crise e as heterotopias de desvio. As heterotopias de crise seriam, portanto, aqueles "lugares privilegiados, ou sagrados, ou proibidos, reservados aos indivíduos que se encontram, em relação à sociedade e ao meio humano no interior do qual eles vivem, em estado de crise" (Foucault, 2001, p. 416), e as heterotopias de desvio, que, segundo o autor, paulatinamente vêm substituindo as heterotopias de crise, seriam aqueles lugares nos quais se localizam "os indivíduos cujo comportamento desvia em relação à média ou à norma exigida" (FOUCAULT, 2001, p. 416).

Nesse contexto, o autor argumenta que tanto as casas de repousos quanto as clínicas psiquiátricas são tipos exemplares das heterotopias de desvio, já que são lugares designados a receber pessoas cujo comportamento desvia em relação à média ou à norma exigida. Mas complementa suas colocações afirmando que são as casas de repouso os lugares que estão "no limite da heterotopia de crise e da heterotopia de desvio, já que, afinal, a velhice é uma crise, mas igualmente um desvio, pois, em nossa sociedade em que o lazer é uma regra, a ociosidade constitui uma espécie de desvio" (FOUCAULT, 2001, p. 416). 
Nessa perspectiva, o conceito de heterotopia de desvio pode muito bem ser aplicado ao espaço simbólico, a loucura, e ao espaço real, a clínica psiquiátrica, destinados à personagem do conto em análise. Aqui, conjecturo que, assim como a velhice, o não exercício da maternidade é uma condição que coloca mulheres como Laura no limite entre a heterotopia de crise e a heterotopia de desvio. A condição de mulher casada sem filhos coloca a personagem em crise e, ao mesmo tempo, faz com que ela represente um desvio, pois, em nossa sociedade, em que o casamento para a mulher é a regra, a impossibilidade de gerar filhos, o não exercício da maternidade, constitui uma espécie de desvio.

Na narrativa, coube a Laura, detentora de um útero infrutífero, encontrar nas limitações do espaço doméstico, no qual se encontrava encerrada, um mecanismo de resistência viável para suportar o peso de não ter sido capaz de realizar o seu potencial criador, cumprindo, assim, seu destino de mulher. Aqui, embarcar no trem da insanidade foi o mecanismo adotado pela personagem para resistir à experiência de representar cotidianamente uma fissura na ordem do sistema patriarcal.

Ainda seguindo essa perspectiva foucaultiana, Tânia Navarro Swain (2007, p. 244) considera que, ao longo do tempo, também os estudos feministas e os movimentos das mulheres — e, aqui, eu acrescentaria também a literatura de autoria feminina — vêm trabalhando para a criação de espaços outros — heterotopias —, práticas e teorias que atuem na representação de gênero e fora dela, na medida da crítica à produção e reprodução do sistema sexo/gênero por meio das instituições sociais. Com base nessas colocações, entendo também que Clarice Lispector em sua produção literária, especialmente na coletânea Laços de Família, não só explora o espaço heterotópico como estratégia literária, mas também trabalha por meio dos seus textos para a criação desses espaços outros.

Nessa narrativa, por exemplo, Clarice Lispector, embora nunca tenha se declarado como uma escritora engajada nas demandas feministas, problematiza a questão da maternidade antes mesmo de as primeiras pensadoras feministas, a exemplo de Simone de Beauvoir ${ }^{6}$, terem

\footnotetext{
${ }^{6}$ De acordo com Navarro-Swain (2007, p. 208), foi a partir das reflexões levantadas por Beauvoir que a maternidade perdeu seu caráter inexorável e que a procriação compulsória foi identificada como uma das chaves do poder patriarcal. Em seu livro $O$ segundo Sexo, publicado em 1949, Beauvoir questiona a noção de feminilidade e de naturalização de comportamentos ancorados no biológico e desnaturaliza a maternidade, apontada no seu trabalho como um mecanismo de opressão e de assujeitamento feminino.
} 
questionado, discutido e desmistificado o desejo de maternidade e o amor materno como essência do feminino. Ainda em seu trabalho Nem musa nem medusa, Lúcia Helena afirma que

[...] não ler o tema da emergência do feminino em Lispector — indicada com fartura por sintomas até de aparente superfície, como se dá com a galeria de mulheres que ela escolhe para protagonizar seus textos - é não ler Clarice Lispector num de seus traços específicos. Considere-se o tratamento que ela oferece à situação contraditória e ambígua das suas personagens femininas e masculinas, que vivem em estado de simultâneo aprisionamento, rebelião e nomadismo, numa sociedade de bases patriarcais (Helena, 1997, p. 27).

Nessa perspectiva, considero que essa observação da pesquisadora abarca o que há de mais singular nos contos de Clarice Lispector, o questionamento sobre a condição feminina em uma sociedade marcadamente patriarcal. Nas narrativas, a emergência do feminino surge nos contos nas passagens em que as personagens femininas vislumbram a possibilidade de fazer escolhas e atribuir um sentido às próprias vidas, escapando da solidão que as afeta nas relações conjugais. Esses aspectos são traços que, desde os primeiros escritos, marcam as obras de Lispector. Em 1940, por exemplo, a autora escreve o conto “A fuga", publicado postumamente na coletânea A bela e a fera (1979), em que narra a história de Elvira, uma mulher casada que questiona o peso de uma relação conjugal estagnada - "Doze anos pesam como quilos de chumbo e os dias se fecham em torno do corpo da gente e apertam cada vez mais. Volto para casa" (LISPECTOR, 1999, p. 73) - e o sentido da própria vida - "Eu era uma mulher casada. Agora sou uma mulher" (LISPECTOR, 1999, p. 71). Nessa narrativa, o casamento é representado como um grande equívoco que conduz as mulheres aos contratos conjugais em nome da estabilidade e do bem-estar, mas acabam aprisionando-as e anulando-as enquanto sujeitos autônomos, capazes de gerir a própria vida.

Nesse sentido, acredito que Clarice Lispector, ao construir personagens femininas que atuam como instâncias críticas aos diversos discursos simbólicos do sistema representacional do patriarcado, sobretudo àqueles intrinsecamente relacionados à instituição familiar e ao contrato conjugal, também trabalha para que a sua produção literária funcione como um espaço outro, heterotópico, que serve, principalmente, para questionar discursos hegemônicos, desestabilizar as noções conservadoras de sexo/gênero e abrir caminho para novas formas de 
representação, que não só questionam esse sistema de base patriarcal, mas trabalham para desestabilizá-lo. Para Lúcia Helena:

\begin{abstract}
Ao questionar a opressão do sujeito declinado no feminino, Lispector rediscute e ilumina um imaginário cultural implantado há séculos, onde reinam, soberanos, padrões de naturalização ideológica do gender. Estabelecendo elos entre a figuração literária do sujeito inscrito no feminino e o campo mais amplo das práticas sociais, Lispector evita, no entanto, os pressupostos de uma estética do reflexo. Em sua obra, ela dá a conhecer que entende a literatura como uma forma de produção de sentido, na qual a construção de identidades de gender não é uma mera forma de reproduzir as desigualdades sociais. Ela compreende que tais identidades repousam sobre relações culturais intersubjetivas e sobre quadros ideológicos de referência, não tendo a ingenuidade de tentar apresentar as suas personagens como representação mais ou menos verdadeira de uma realidade feminina pré-dada e externa ao texto (HELENA, 1997, p. 28).
\end{abstract}

Clarice Lispector, no que se refere à representação da personagem feminina casada, tece nas narrativas da coletânea Laços de Família uma reflexão que discute a inscrição do sujeito na história ao adotar, por exemplo, recursos como o silenciamento, a acomodação e, nesse conto, a loucura que abate o sujeito feminino como estratégias para problematizar não só a singular emergência da mulher na sociedade, marcada por enorme repressão, mas, principalmente, para questionar as questões culturais, como os aparatos discursivos institucionalizados pelo patriarcado, imbricadas no processo de apagamento da mulher como sujeito da história.

Diversos trabalhos sobre as obras de Clarice Lispector apontam para o fato de as suas personagens tenderem à recorrer a diferentes estratégias, como, por exemplo, a acomodação, a loucura, a morte, para resistir aos mecanismos de opressão do sistema sexo/gênero, caracterizados nessas narrativas por diferentes dispositivos discursivos, como a ideia de amor romântico e o dispositivo da escolha, no caso de Ana, ou a maternidade obrigatória, no caso de Laura. Em “A Imitação da Rosa”, a personagem encontra na loucura a sua estratégia para resistir ao estigma de carregar um útero infrutífero e não atender às expectativas sociais associadas às mulheres presas a uma relação conjugal fundada em valores de bases patriarcais. Assim, Laura pode ser compreendida como uma personagem que, ao lado de Anas, Elviras, Joanas, Lóris, atuam como instâncias críticas a diversos discursos simbólicos do sistema representacional do patriarcado - dispositivo da escolha, ideal de amor romântico e, neste conto, aos sentidos 
sociais atrelados à maternidade — que são responsáveis por tornar, sobretudo, o casamento um lugar de aprisionamento e de anulação do sujeito feminino.

\section{REFERÊNCIAS}

FOUCAULT, M. "Outros espaços". In: Ditos \& Escritos. vol. III. Rio de Janeiro: Forense Universitária, 2001.

HELENA, L. Nem musa, nem medusa: itinerários da escrita em Clarice Lispector. Niterói: EDUFF, 1997.

HEILBORN, M. L. “Amor, conjugalidade e família: traição e violência têm vez?”. In: Mulheres brasileiras e gênero nos espaços público e privado: uma década de mudanças na opinião públical Gustavo Venturini e Tatau Godinho (orgs.); prefácio Eleonora Menicucci. - São Paulo: Editora Fundação Perseu Abramo: Edições Sesc SP, 2013, 504 p.

HOMEM, M. L. "A Imitação da Rosa - Encontro com o silêncio ou encontro com o feminino e a falta". In: Leitores e leituras de Clarice Lispector / organização Regina Pontieri. São Paulo: Hedra, 2004.

LAURETIS, T. de. "A tecnologia do gênero". Trad. de Susana Borneo Funck. In: HOLLANDA, Heloísa Buarque de (org.). In: Tendências e impasses: o feminismo como crítica da cultura. Rio de Janeiro: Rocco, 1994.

LISPECTOR, C. "Vida". Disponível em: < http://claricelispectorims.com.br/Home>. Acesso em: 17 jun. 2013.

LISPECTOR, C. A bela e a fera. Rio de Janeiro: Rocco, 1999.

LISPECTOR, C. Amor. In: Laços de Família. Rio de Janeiro: Rocco, 2009.

LISPECTOR, C.A imitação da rosa. In: Laços de Família. Rio de Janeiro: Rocco, 2009.

LISPECTOR, C. Os obedientes. In: Felicidade Clandestina. Rio de Janeiro: Rocco, 1998, 1. ${ }^{\text {a }}$ edição.

MAIA, C. A invenção da solteirona: conjugalidade moderna e terror moral: Minas Gerais, 18901948/ Cláudia de Jesus Maia. - Ilha de Santa Catarina: Ed. Mulheres, 2011.

NAVARRO-SWAIN, T. "Meu corpo é um útero? Reflexões sobre a procriação e a maternidade". In: Maternidade e Feminismo: diálogos interdisciplinares/ organizadora Cristina Stevens. - Florianópolis: Ed. Mulheres; Santa Cruz do Sul: Edunisc, 2007.

OLIVEIRA, P. P. A construção social da masculinidade. Belo Horizonte: Ed. UFMG; Rio de Janeiro: IUPERJ, 2004.

SCHMIDT, R. T. Cânone/ Contra - Cânone: Nem aquele que é o mesmo nem este que é o outro. Rita Terezinha e CARVALHAL, Tânia (orgs.) In: O discurso crítico na América Latina. São Leopoldo: Editora Unisinos, 1996. 
SCHMIDT, R. T. Refutações ao feminismo: (des)compassos da cultura letrada brasileira. In: Revista Estudos Feministas v.14, nº 3. Florianópolis, setembro-dezembro de 2006, pp.765-99.

ZOLIN, L. O. Literatura de Autoria Feminina. In: Teoria Literária: abordagens históricas e tendências contemporâneas. Organização Thomas Bonnici, Lúcia Osana Zolin. 3 ed. rev. e amp. Maringá: Eduem, 2009a.

ZOLIN, L. O. Crítica Feminista. In: Teoria Literária: abordagens históricas e tendências contemporâneas. Organização Thomas Bonnici, Lúcia Osana Zolin. 3 ed. rev. e amp. Maringá: Eduem, 2009b. 